\title{
Study on the erosion wear in pipe fittings
}

\author{
Manlai Zhang***, Qin Zhang******, Xiuwu Wang***, Zhihong Zhou* and Ruiquan \\ Liao $* * * *$ \\ * School of Mechanical Engineering, Yangtze University, Jingzhou, China \\ ** Key Laboratory of Exploration Technologies for Oil and Gas Resources, Ministry of Education, Yangtze University, Jingzhou, China \\ *** Faculty of Chemical Engineering Kunming, Kunming University of Science and Technology, Yunnan, China \\ **** The Branch of Key Laboratory of CNPC for Oil and Gas Production, Yangtze University, Jingzhou, China \\ ****** Corresponding Author: 447167633@qq.com
}

Submitted : 28/06/2019

Revised :27/10/2020

Accepted :09/11/2020

\begin{abstract}
In the pipeline system for slurry, local erosion wear failure has become the main damage mechanism of pipe in the fracturing operations of oil-gas engineering. Computational Fluid Dynamics simulation is performed to determine the evolutionary process of erosion wear in tubing connector, which is the resistance of pipeline system, and a new way to predict the pipeline longevity is provided. Based on the Euler equation, solid particle concentration in the slurry and interphase momentum exchange are included in the liquid flow equations due to the influence of dense particle on slurry (slurry is a two-phase flow), and the particle trajectory was calculated in the Lagrange frame by analyzing the forces from the interaction of liquid and particle and particles impact. With the erosion damage model, the erosion rate/depth in the connector was calculated to reconstruct the mesh model of shoulder with 5 tori. Torus 1 is closest to axis while torus 5 is on the outmost wall of the connector. During the erosion event, greatest erosion and hence surface deformation occurs on tori 1 and 2, and this affects the surrounding flow and particle movement. After 10 hours of erosion, there was a dramatic drop in the maximum erosion rate, which illustrated a conservative prediction for pipeline service life if the initial erosion rate was used. An erosion experimental setup was also performed to identify the weight loss and erosion characteristic of the inner surface with erosion time of 55 hours. It was observed that the erosion simulations provided relative errors within $18 \%$ for erosion length and weight loss compared to the experimental values, and a closed form equation for the erosion rate was proposed to predict the erosion life of tubing connector.
\end{abstract}

Keywords: Slurry erosion; Impact; steel; Erosion testing; Numerical simulation.

\section{NOMENCLATURE}

$\mu \quad$ liquid viscosity

K $\quad$ consistency coefficient

n flow index 


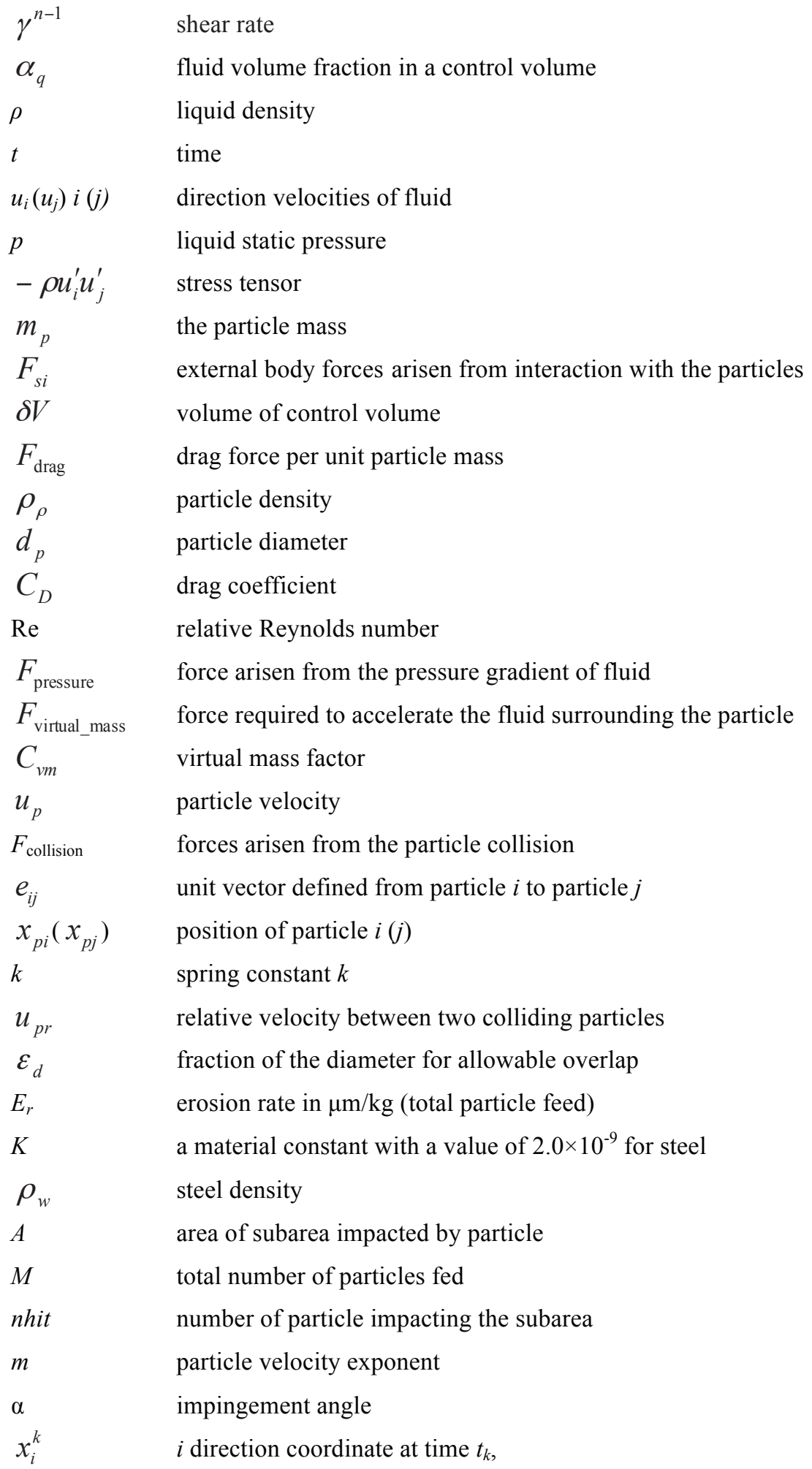




$\begin{array}{ll}x_{i}^{0} & \text { original coordinate } \\ e_{i} & \text { unit } i \text { direction location vector } \\ n_{i}^{j} & \text { unit outward normal vector of small area at time } t_{\mathrm{j}} \\ d x_{i}^{j} & \text { erosion deformation at the } j \text { time period }\left[t_{\mathrm{j}-1}, t_{\mathrm{j}}\right] \\ E_{r j} & \text { erosion rate at time } t_{\mathrm{j}}\end{array}$

\section{INTRODUCTION}

Erosion wear is a common phenomenon of slurry flow in pipe, which can remove material from the wall due to the impact of particles, and the thickness reduction caused by erosion is an important consideration in design and safety evaluation of pipe. The method to test the weight loss of the pipe has been widely used to identify the erosion level (Finnie, 1960; Tilly, 1979), but the evolution of erosion characters in the inner surface cannot be obtained through the test. Nowadays, the numerical simulation method for particle movement has been realized by combing multiphase flow model with erosion model to predict the wall erosion for the pipe fittings (such as bend and connector) (Huser et al., 1998; Majumder 2015; Ping et al., 2017; Guofu et al., 2018), and detailed information about erosion position and erosion rate could be obtained (Mazumder et al., 2005; Joseph et al., 2009). Chong et al. (2013) employed Computational Fluid Dynamics (CFD) method to simulate the flow field and the erosion characteristics on the surface of annular with the Euler-Lagrange method (Badr et al., 2005; Davis et al, 2009) based on the fixed mesh model. Combined with the overall erosion distribution features on surfaces, the erosion rate was predicted, but it was significantly overpredicted up to $100 \%$ of experimental values by the $38 \mu \mathrm{m}$ sized particles on the forward-facing step. Because the wear deformation of the inner wall is ignored during the simulation progress, the method mentioned above is only available for the initial stage of erosion, which has a negligible effect on the flow field (Man-Lai et al., 2011). Obviously, the erosion wear on the inner wall is accumulated to affect the flow in pipe eventually, and interaction of flow and wall deformation should be considered for determining the evolutionary process of erosion wear, according to which the erosion life of pipe can be precisely attained. The purpose of the current work was to predict the erosion wear of the tubing connector by using mesh reconstruction technique to simulate the erosion deformation on wall, and the obtained simulation result was compared with the experimental data.

\section{METHODS}

\subsection{Experiment}

In order to investigate the erosion of a horizontal pipe by silica sand (Figure 1), an experimental rig was built (Figure 2). The fracturing fluid, which is used for fracturing in oil and gas fields, is pumped into a horizontal pipe by piston pump, forming a loop through the high pressure pipe. The flow is controlled by electric control valve and measured by flowmeter. The pressure drop of tubing is determined by measuring the inlet and outlet pressure of tubing with pressure gauge. To avoid the slurry settlement during experiments, the fracturing fluid must be continuously stirred in the agitator tank. 


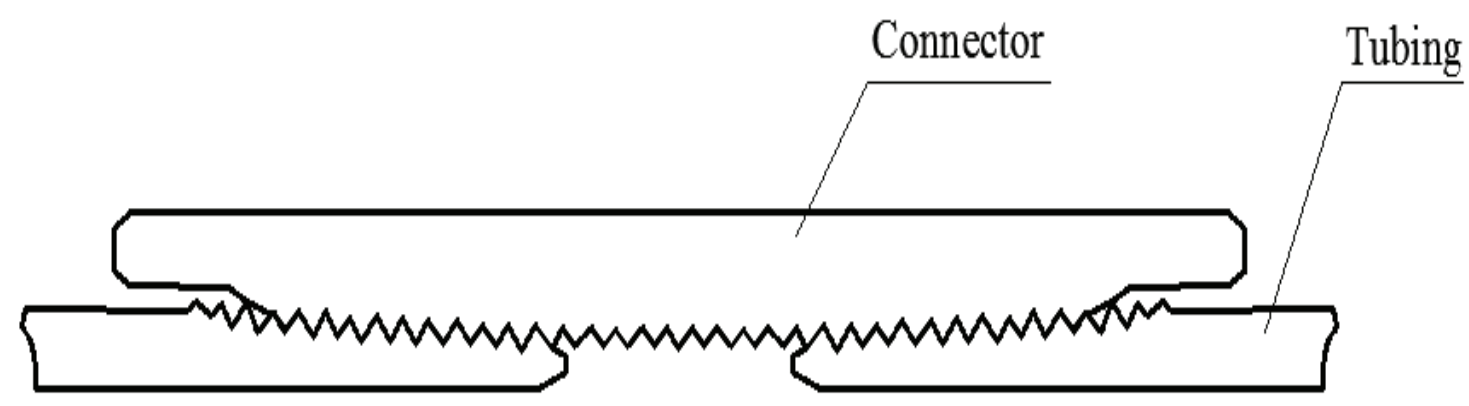

Figure 1. The structure of tubing connector.

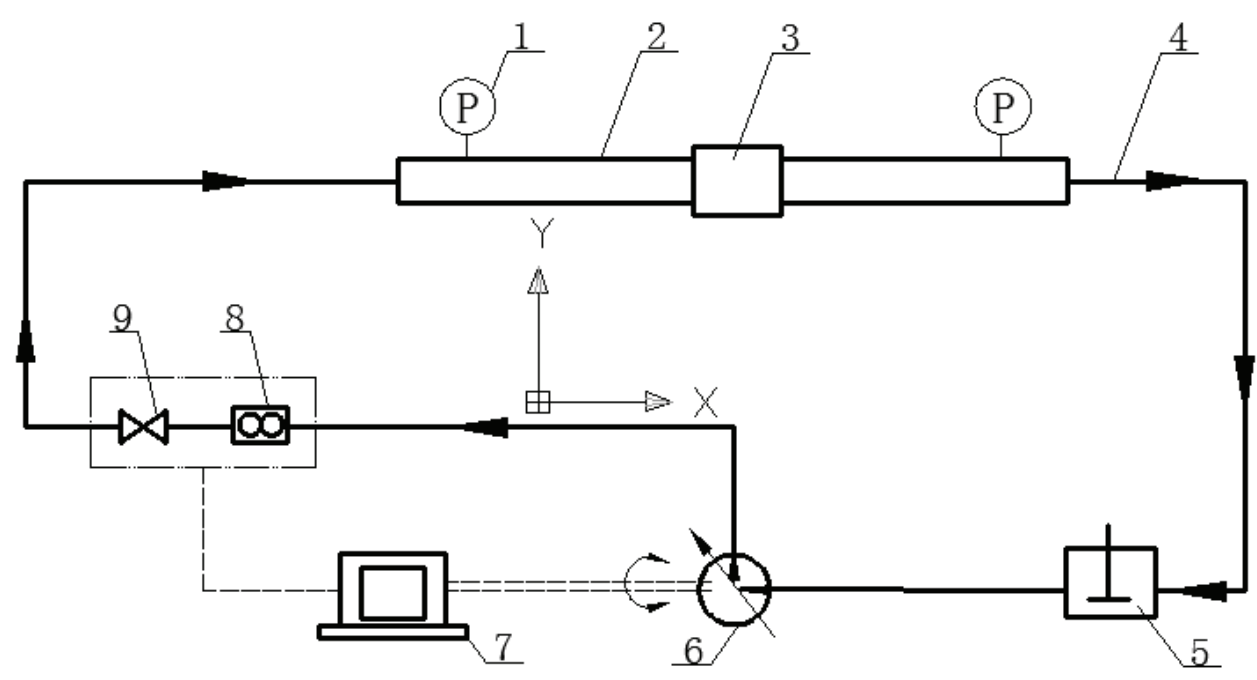

Figure 2. Schematic diagram of experimental rig for tubing connector.

1 - Pressure gauge; 2 - Tubing; 3 - Connector; 4 - High pressure pipe; 5 - Agitator tank; 6 - Piston pump; 7 - Control system; 8 - Flowmeter; 9 - Electric control valve.

By using screen mesh, the grain size of silica is filtered to $150 \mu \mathrm{m}$, and the particle volume fraction is $26 \%$. As the infusion is non-Newtonian fluid, viscosity varies with rotational speed and is measured by a torque rheometer, revealing that the rheological behavior of fracturing fluid obeys the Non-Newtonian power law properly, and it is described as (Mitsoulis, 2007)

$$
\mu=K \gamma^{n-1}
$$


When the experimental temperature is $35^{\circ} \mathrm{C}, n$ is 0.651 , and $K$ is $29.01 \mathrm{mPa} . \mathrm{s}^{\mathrm{n}}$. Considering the temperature rise caused by circulating flow in the experimental pipeline, the liquid temperature is monitored, in case experimental temperature deviated greatly from the reference value $\left(35^{\circ} \mathrm{C}\right)$. Once the temperature reaches $38^{\circ} \mathrm{C}$, the pump stops running. When the total time of several erosion experiences reaches the setting, the weight loss of connector is measured with electronic scale, and the connector is slit to show the erosion characteristic.

\subsection{Numerical Simulation}

\subsubsection{The Fluid Flow Model}

The complete model for the erosion wear consists of the fluid flow equations, the particle motion equation and erosion damage model. When the particle volume fraction is low $(<10 \%)$, the Discrete phase model (DPM) (Noon et al., 2016) is appropriate to describe the dilute particle flow because the influence of particle on liquid flow can be ignored. However, solid particle concentration in the fracturing fluid is high enough to affect the liquid flow, so the flow equations should be modified by including the item related with the particle volume fraction and interphase momentum exchange. It is described as (Hager et al., 2018)

$$
\begin{aligned}
& \frac{\partial\left(\alpha_{q} \rho\right)}{\partial t}+\frac{\partial\left(\alpha_{q} \rho u_{j}\right)}{\partial x_{j}}=0 \\
& \frac{\partial}{\partial t}\left(\alpha_{q} \rho u_{i}\right)+\frac{\partial}{\partial x_{j}}\left(\alpha_{q} \rho u_{i} u_{j}\right)=-\alpha_{q} \frac{\partial p}{\partial x_{i}}+\alpha_{q} \rho g_{i}+\frac{\partial}{\partial x_{j}}\left(\alpha_{q} \mu \frac{\partial u_{i}}{\partial x_{j}}\right)-\frac{\partial}{\partial x_{j}}\left(\alpha_{q} \rho u_{i}^{\prime} u_{j}^{\prime}\right) \\
& +\frac{F_{s i} \cdot m_{p}}{\delta V}
\end{aligned}
$$

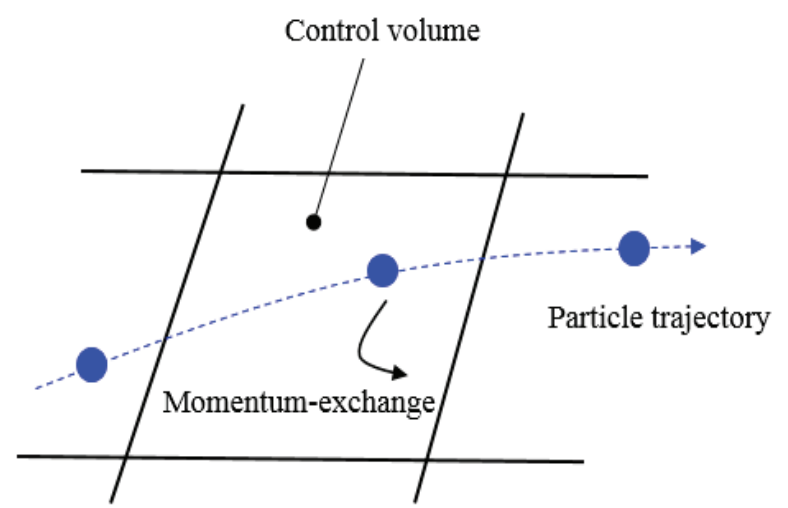

Figure 3. Momentum transfer between fluid and particle.

As shown in Figure 3, the momentum transfer from the fluid to the particle is determined by examining the change in momentum of a particle as it passes through each control volume. This momentum change equals the external force, and is described by (Noon et al., 2016) 
$F_{\mathrm{si}}=\sum\left(F_{\text {drag }}+F_{\text {pressure }}+F_{\text {virtual_mass }}\right)$

where $F_{\text {drag }}$ is computed as follows (Haider et al., 1989):

$$
F_{\text {drag }}=\frac{3 \mu C_{D} \operatorname{Re}}{4 \rho_{p} d_{p}^{2}}\left(u_{\mathrm{i}}-u_{p \mathrm{i}}\right)
$$

Re can be written as (Mitsoulis, 2007):

$$
\begin{gathered}
\operatorname{Re}=\frac{\rho_{p} d_{p}\left|u_{p i}-u_{i}\right|}{\mu} \\
F_{\text {pressure }} \text { is computed as follows (Cundall et al., 1979): } \\
F_{\text {pressure }}=\frac{\rho}{\rho_{p}} u_{p} \frac{\partial u_{j}}{\partial x_{j}} \\
F_{\text {virtual_mass }} \text { is described as (Cundall et al., 1979): } \\
F_{\text {virtual_mass }}=C_{v m} \frac{\rho}{\rho_{p}}\left(u_{p} \frac{\partial u_{j}}{\partial x_{j}}-\frac{d u_{p}}{d t}\right)
\end{gathered}
$$

Additionally, when the flow is turbulent, the k- $\varepsilon$ model is used for turbulence modeling.

\subsubsection{The Particle Motion Equation and Erosion Damage Model}

Particle motion is determined by solving the particle motion equation in Lagrange frame (Hager et al., 2018),

$$
\frac{d u_{p}}{d t}=-F_{s i}+\frac{g_{x}\left(\rho_{p}-\rho\right)}{\rho_{p}}+\sum_{i=1}^{n} F_{\text {collisioni }}
$$

where $\sum_{i=1}^{n} F_{\text {collisioni }}$ is determined by the deformation, which is measured as the overlap between pairs of particles.

$$
e_{i j} \quad \text { is expressed as (Hager et al., 2018): }
$$




$$
e_{i j}=\left(x_{p i}-x_{p j}\right) /\left\|x_{p i}-x_{p j}\right\|
$$

The overlap $\delta_{i j}$ (which is less than zero during contact) is defined as follows (Hager et al., 2018):

$$
\delta_{i j}=\left\|x_{p i}-x_{p j}\right\|-\left(d_{p i}+d_{p j}\right)
$$

Following the spring collision law of the discrete element method (DEM), the force on particle is computed as follows (Hager et al., 2018):

$$
F_{\text {collisioni }}=k \delta_{i j} e_{i j}
$$

Here, the value of $k$ can be estimated with the following equation (Hager et al., 2018),

$$
k=d_{p} \rho_{p} \frac{\pi u_{p r}^{2}}{3 \varepsilon_{d}^{2}}
$$

Equation 9 is integrated in a time step of $\pi \sqrt{m_{p} / k}$ to capture the trajectory of a particle. When the particle repeatedly impacts the wall and exceeds the shear strength of steel, a cut is formed on the surface (Wong, 2013). Erosion rate model for a subarea is given as follows (Bitter 1963; Haugen et al 1995):

$$
E_{r}=\frac{10^{6} K}{\rho_{w} A M} \sum_{i=1}^{n h i t} u_{i}^{m} F\left(\alpha_{i}\right)
$$

Here, the erosion rate $E_{r}$ is erosion depth due to impact of $1 \mathrm{~kg}$ particle on this microplane. Haugen et al. (1995) have done the test for determining the material related parameters and $F(\alpha)$ relation depending on impingement angle (seen Table 1 and Figure 4).

Table 1. Material-dependent parameters for steel grade.

\begin{tabular}{|c|c|c|c|}
\hline Material & $\mathbf{K}$ & $\mathbf{n}$ & $\boldsymbol{\rho}_{\mathbf{w}}$ \\
\hline Steel grade & $2.0 \times 10^{-9}$ & 2.6 & $7800 \mathrm{~kg} / \mathrm{m}^{3}$ \\
\hline
\end{tabular}




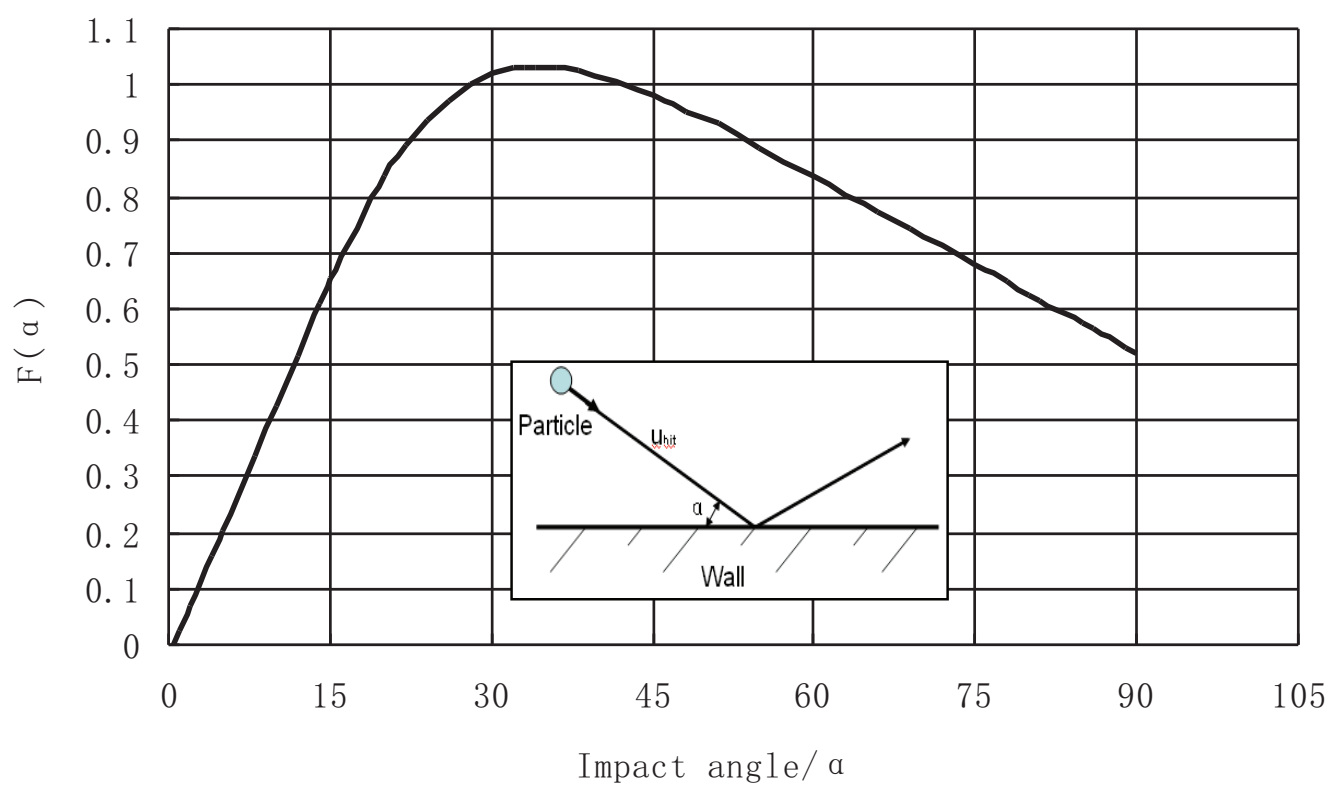

Figure 4. $F(\alpha)$ functional relationship (Haugen et al. 1995).

\subsubsection{The Calculation Method and Process}

For the unsteady flow simulation, the finite volume method (FVM) and PISO algorithms (Wong et al. 2013) are adopted to derive and solve the discrete equations of fluid flow on a staggered grid.

The fluid-particle coupling simulation is described as follows:

(1) Calculate the fluid flow equations until a converged solution is achieved in one time step, then uniformly launch $N$ number of particles from the inlet surface $(N=2000)$.

(2) Solve the particle motion equation to get velocity and position of each particle, and then calculate Equation 14 to identify the erosion depth in each wall mesh face.

(3) Repeat steps (1) (2) until the number of total particles escaping through the outlet is equal to $M$ $(M=234000)$.

(4) Calculate Equation 14 to identify the erosion rate and erosion depth for a given time period $\left[0, t_{1}\right]$, and reconstruct the mesh model for next simulation period $\left[t_{1}, t_{2}\right]$.

(5) Repeat steps $(1) \sim(4)$ to obtain the erosion rate and erosion depth at successive time point $t_{3}, \ldots, t_{n}$.

During the process of mesh reconstruction, the new location of center is updated according to

$$
x_{i}^{k}=x_{i}^{0}+\sum_{j=1}^{k-1} d x_{i}^{j}\left(e^{j} \cdot n_{i}^{j}\right)
$$

Here, $d x_{i}^{j}=E_{r j} \cdot\left(t_{j}-t_{j-1}\right)$ 


\section{RESULTS AND DISCUSSION}

The liquid-solid flow model and erosion model were combined to simulate the flow field and erosion rate in a tubing connector. The connector with a horizontal inlet and horizontal outlet is shown in Figure 5. Some assumptions were made for simulation, including the fracturing fluid that is incompressible and the particles that are round and uniform in size. Table 2 shows the relevant parameters.

Table 2. Relevant flow parameters.

\begin{tabular}{|c|c|}
\hline Description & Condition \\
\hline Inlet liquid flow velocity & $20 \mathrm{~m} / \mathrm{s}$ \\
\hline Outlet pressure & $0 \mathrm{~Pa}$ \\
\hline Fracturing fluid density & $1200 \mathrm{~kg} / \mathrm{m}^{3}$ \\
\hline Tubing inner diameter & $45.34 \mathrm{~mm}$ \\
\hline Tubing outer diameter & $60.32 \mathrm{~mm}$ \\
\hline Model length & $1200 \mathrm{~mm}$ \\
\hline Particle diameter & $150 \mu \mathrm{m}$ \\
\hline Particle density & $2650 \mathrm{~kg} / \mathrm{m}^{3}$ \\
\hline Flow pattern & Horizontal \\
\hline
\end{tabular}
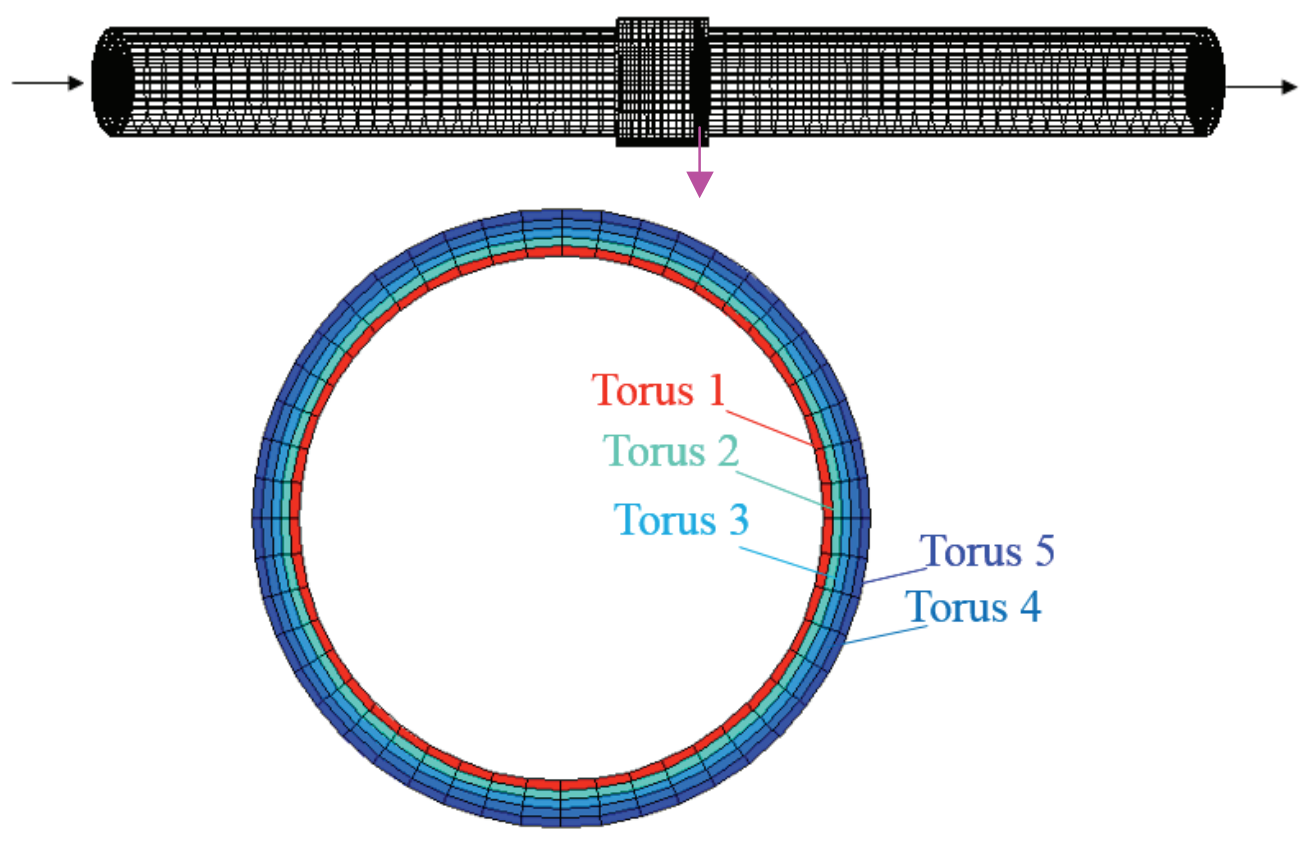

Figure 5. CFD mesh model (33880 hexahedral element). 


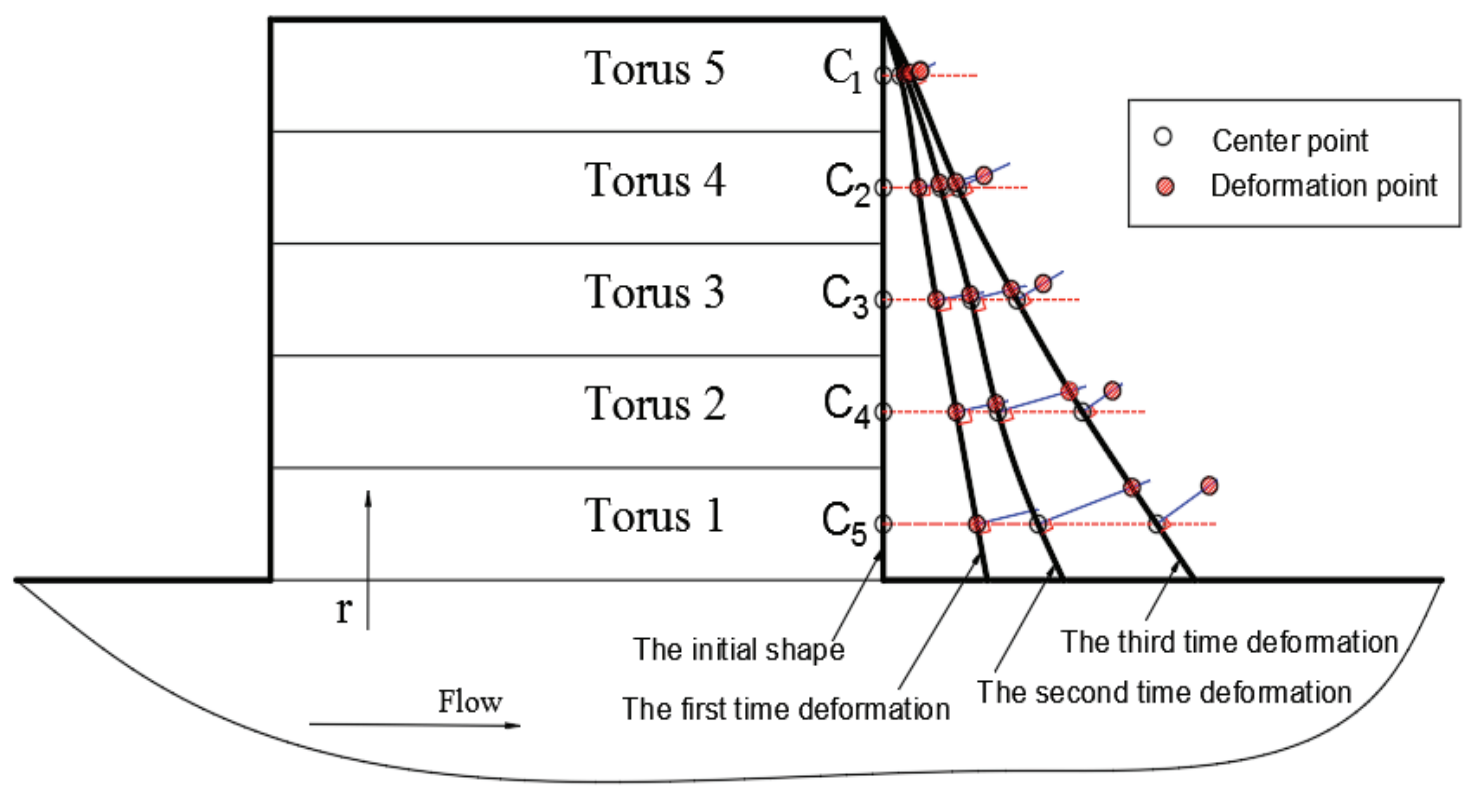

Figure 6. Schematic diagram of new shoulder generatrix for model reconstruction.

For the convenience of simulation, the axial symmetry of structure is considered, and the shoulder surface, which has the most serious erosion zone, is evenly divided into five tori as shown in Figure 5, and the center points in each torus were marked with $\mathrm{C}_{1} \sim \mathrm{C}_{5}$ (Figure 6). After calculating the erosion rates of mesh faces, the erosion depths of center points $\left(\mathrm{C}_{1} \sim \mathrm{C}_{5}\right)$ are identified following the erosion rates of area-weighted average for each torus, and the deformation points were, respectively, located by moving the center points along the normal direction of each torus with the erosion depth. Then, the new shoulder generatrix after an erosion time period is formed by connecting deformation points with Bézier curve.

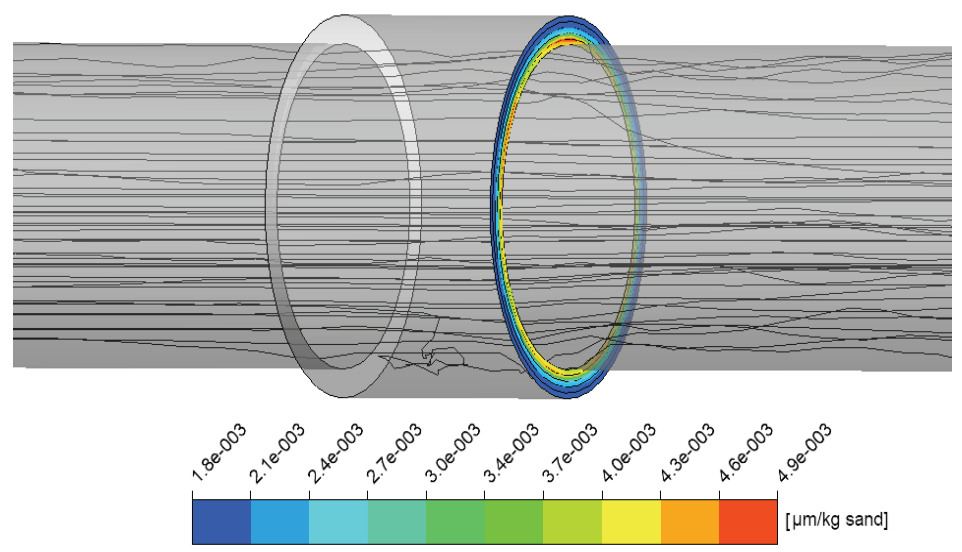

(a) 

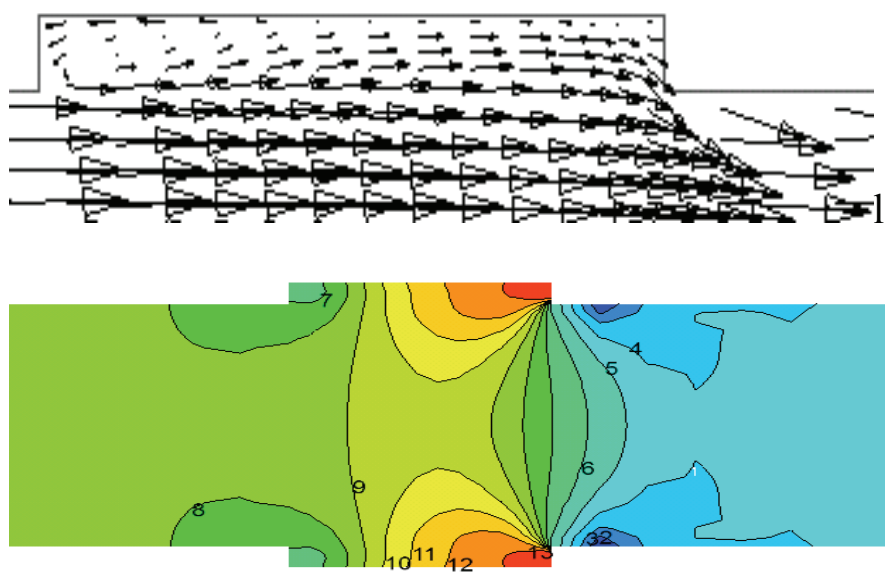

(b)
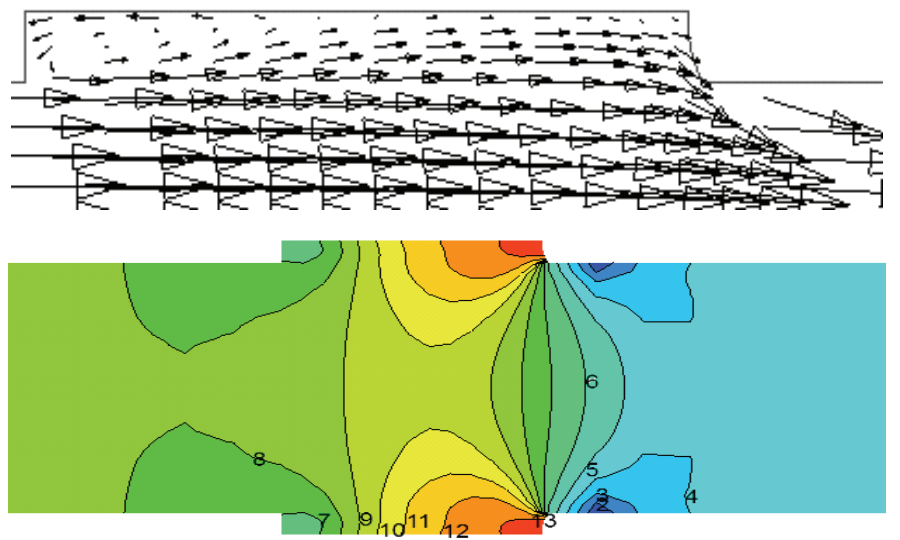

(c)
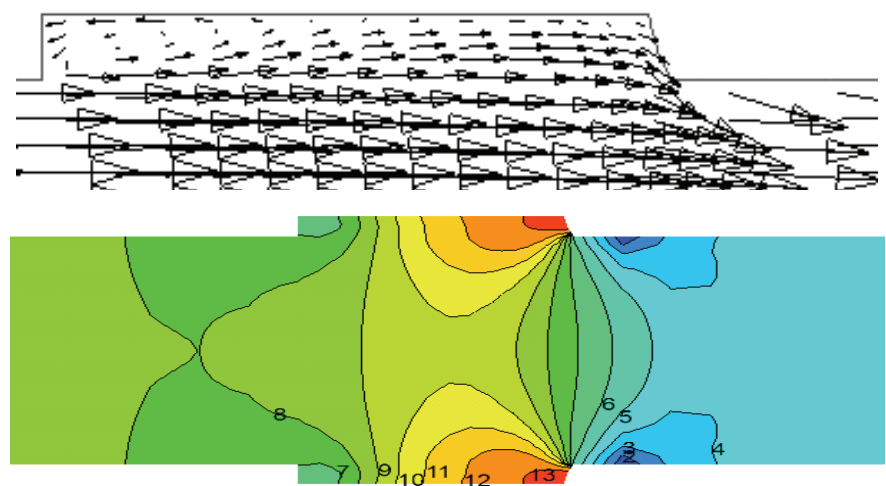

(d) 


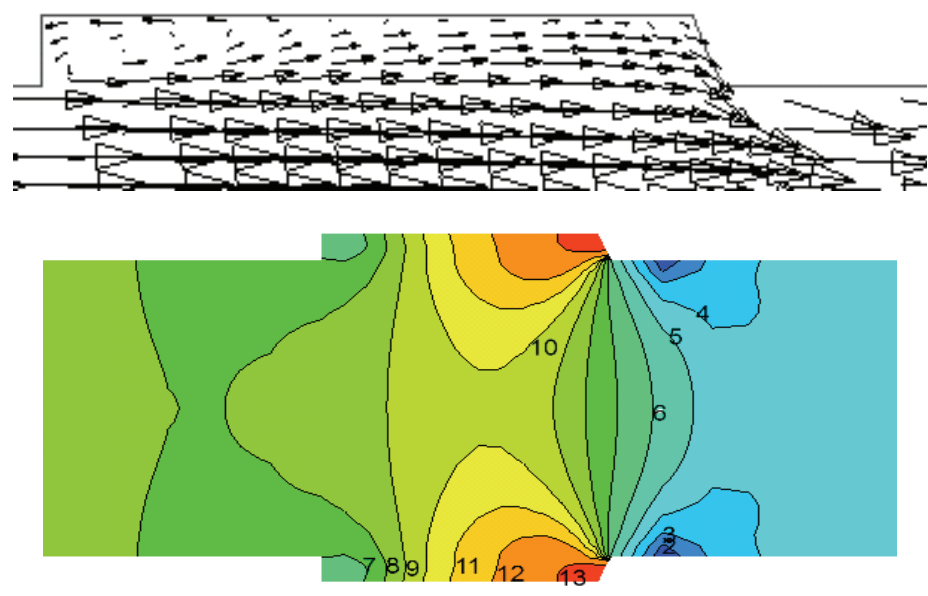

(e)

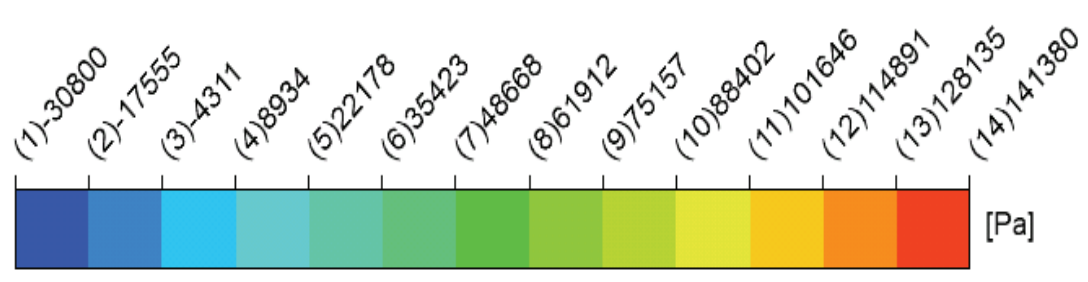

Figure 7. Erosion deformation and flow field at different time (a) particle trajectory and erosion rate contours without erosion deformation; (b) flow field without erosion deformation; (c) flow field with erosion (15 h); (d) flow field with erosion $(35 \mathrm{~h})$; and (e) flow field with erosion $(55 \mathrm{~h})$.

Figure 7 shows the particle trajectory and flow field with the erosion wear at the connector. As particle impacts the right shoulder, its trajectory is bended and extended to the straight pipe (Fig. 7a). Obviously, the erosion on the right side of the connector is much more severe than that of the left side. Fig. 7b shows the flow field without erosion deformation. As for connector, the velocity of the fluid flow near the wall is small; meanwhile, the backflow appears on the left shoulder, while the velocity increases on the right shoulder. The maximus pressure on the wall is $141380 \mathrm{~Pa}$. During the process of erosion, the right shoulder surface of the connector changes from vertical plane to oblique surface with respect to flow direction (Fig. 7c 7e), indicating that the shape of the right shoulder surface was streamlined by the continuous impact of particles. With the streamlined shoulder, the pressure at the connector junction decreases, and the zone of highest pressure contracts away from the center of pipe. Simultaneously, the upstream pressure declines with the isobaric line 14 extending to the pipe center, and the pressure marked with 10 tends to rise.

Figure 8 shows the erosion deformations of the right shoulder surface at different times. Torus 1 has the maximum erosion deformation and decreases progressively to torus 5 . When the connector has been eroded for $5 \mathrm{~h}$, torus 1 becomes more streamlined, and torus 2 is in severe erosion state and is slightly deformed. At the $15^{\text {th }}$ hour of erosion, the shape of torus 2 has changed to be streamlined with an inflection point between torus 1 and torus 2 . This makes torus 1 to be the serious erosion target again. When time exceeds $35 \mathrm{~h}$, the total surface of right shoulder is streamlined, and the erosion deformation changes more slightly. Therefore, it is interesting to note that the slurry 
has a greater destructive effect on the connector in the early stages of erosion, and the structure is reshaped into a streamlined shape as the result of the cumulative erosion over a long time.

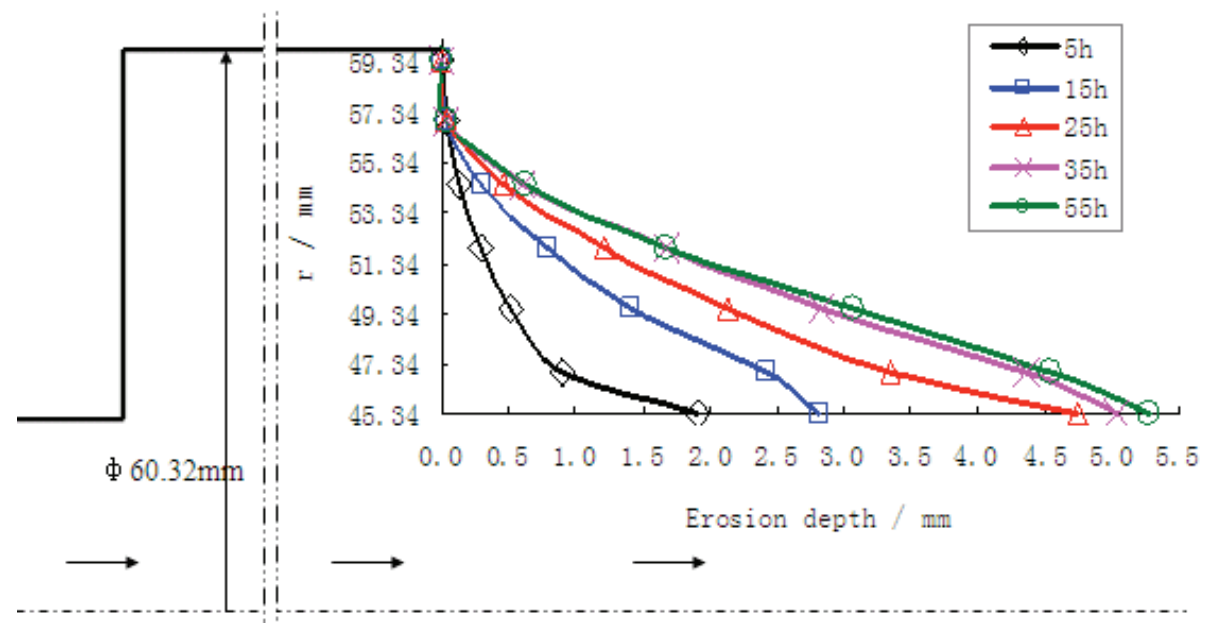

Figure 8. Erosion deformation of right shoulder surface at different time.

Figure 9 shows the variation of the average erosion rate of each torus with time. The torus that is close to the center of the pipe has the higher erosion rate. The erosion rate of torus 1 is $4.07 \times 10^{-3} \mu \mathrm{m} / \mathrm{kg}$ sand at the beginning; then, when the sharp corner at junction is eroded and tends to streamline, the impact strength of particles is weakened, which makes the erosion rate decreases sharply. As the right shoulder surface becomes more and more streamlined, the erosion rate tends to be stable. Furthermore, due to the continuous destruction shape of Torus 1 , the flow field and particle trajectory change accordingly, resulting in fluctuation of erosion rate in a certain extent.

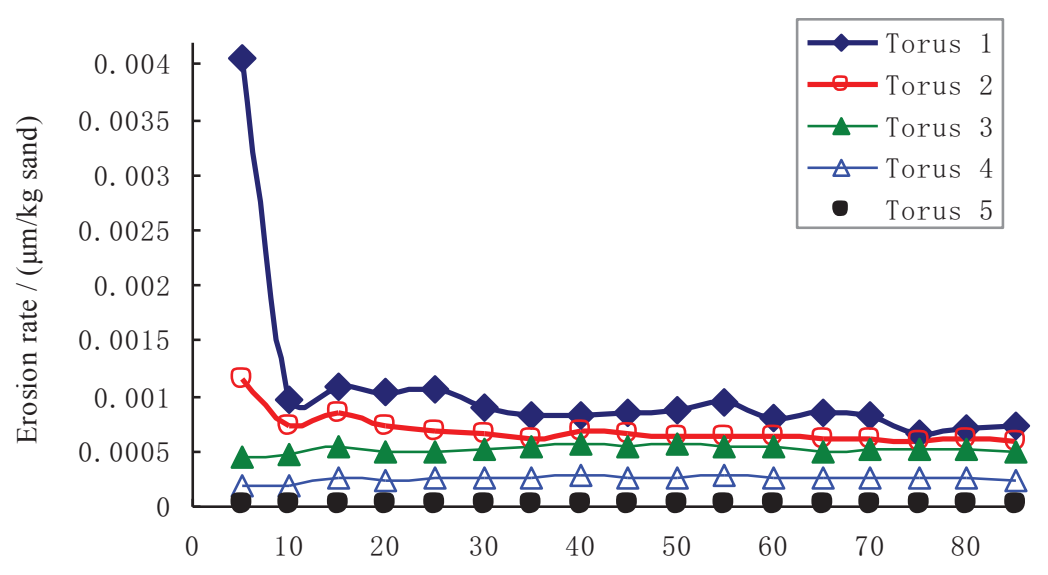

Time / h

Figure 9. Average erosion rates of five tori. 


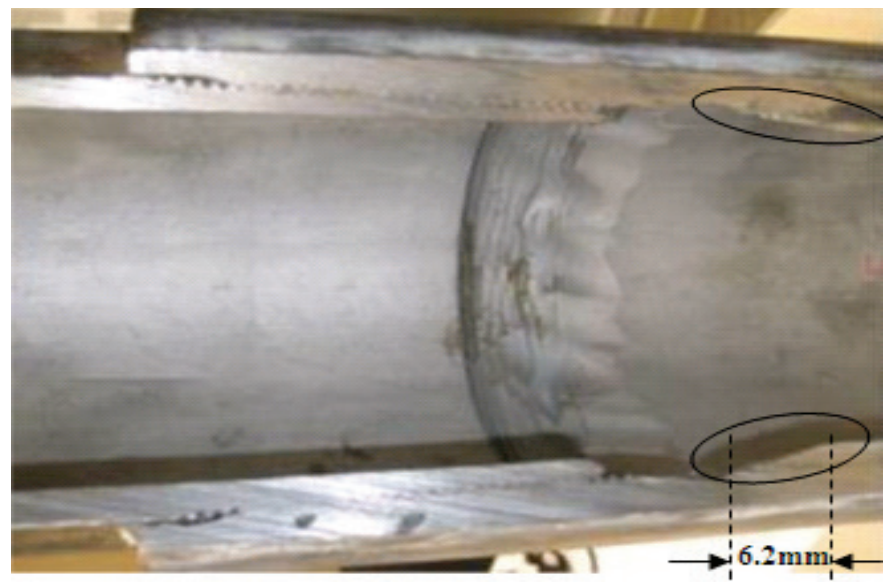

Figure 10. Axial erosion length test (erosion time is $55 \mathrm{~h}$ ).

Figure 10 shows the erosion of connector. It is more like the axial oblique cutting traces at the right shoulder. After 55 hours of erosion, the experimental axial erosion length and weight loss are $6.2 \mathrm{~mm}$ and $0.243 \mathrm{~kg}$, respectively, while the predicted results are $5.25 \mathrm{~mm}$ and $0.20 \mathrm{~kg}$. The corresponding relative errors are $15.3 \%$ and $17.7 \%$, respectively, which preliminarily verifies the reliability of the simulation method. Obviously, if the erosion deformation is not considered, the calculated erosion length and weight loss are much higher.

\section{CONCLUSIONS}

In summary, we have used numerical techniques and erosion model to predict the erosion wear in the tubing connector. In the simulation, several important interactions of liquid-particle, particle-particle, and fluid-structure were considered, and the mesh model of connector was reconstructed according to the wall erosion deformation.

The particle trajectory and the transient erosion deformation, which still cannot be approached through the test, were obtained through the simulation, and the peak average erosion rate was found to occur on the inner wall of junction. It was found that the connector shoulder surface extends to be streamlined when the erosion was significant for large amount of sand feed, and the peak erosion rate decreases dramatically from the $4.07 \times 10^{-3}$ $\mu \mathrm{m} / \mathrm{kg}$ sand. After 55 hours of erosion, the maximal erosion length and the weight loss from simulation are equal to $5.25 \mathrm{~mm}$ and $0.20 \mathrm{~kg}$, respectively, which show basic agreement with the experiment results.

The study shows the method of transient simulation for the erosion wear and helps improve the prediction of the erosion safety for connector in service.

\section{ACKNOWLEDGMENT}

This study was supported by the Educational Commission of Hubei Province of China (B2016032), the National Natural Science Fund Project (61572084), and the 13th Five-Year Major National Major Projects (Grant No.2017ZX05030-005). 


\section{REFERENCES}

Finnie. 1960. Erosion of surfaces by solid particles. Wear 3: 87-103.

G.P. Tilly. 1979. Erosion by impact of solid particles. Treatise on Material Science and Technology. Academic Press. New York.

Huser, A. \& Kvernvold, O. 1998. Prediction of sand erosion in process and pipe components. 1st North American Conference on Multiphase Technology, Canada.

A. K. Majumder. 2015. Modeling fluid-particle interactions in flowing film type gravity concentrators. Journal of Engg. Research 4: 1-16.

Ping, L., Yang, Z., Bin, L., Guan-Xin, Z., Tao, Z., Dake, X., Hong, G., Ting-Yue, Gu. \& Fu-Hui W. 2017. Experimental testing and numerical simulation to analyze the corrosion failures of single well pipelines in Tahe oilfield. Engineering Failure Analysis 80:112-122.

Guofu, O., Kainian, B., Zhi-Jian, Z., Ge-Ping, S., Chao, W. \& Bo, C. 2018. Numerical simulation on the erosion wear of a multiphase flow pipeline. Int J Adv Manuf Technol 96: 1705-1713.

Mazumder, Q., Shirazi, S., McLaury, B., Rybicki, E. \& Shadley, J. 2005. Development and validation of a mechanistic model to predict solid particle erosion in multiphase flow. Wear 259: 203-207.

Joseph I. Achebo. 2009. Computational analysis of erosion wear rate in a pipeline using the drift flux models based on eulerian continuum equations. Proceedings of the World Congress on Engineering WCE 2009. London.

Wong, Y., Christopher, S., Anthony, S. \& Jie, W. 2013. Experimental and computational modeling of solid particle erosion in a pipe annular cavity. Wear 15: 109-129.

Badr, H.M., Habib, M.A. \& Ben-Mansour, R. 2005. Numerical investigation of erosion threshold velocity in a pipe with sudden contraction. Computer sand Fluids 34: 721-742.

Davis, C. \& Frawley, P. 2009. Modelling of erosion-corrosion in practical geometries, Corrosion Science 51, 769-775 April

Man-Lai, Z., Rui-Quan, L. \& Jin, F. 2011. Prediction of particle erosion in bend based on Liquid-solid coupling simulation, ICPTT 2011: Sustainable Solutions for Water, Sewer, Gas, and Oil Pipelines Proceedings of the International Conference on Pipelines and Trenchless Technology. 542-551.

Mitsoulis, E., 2007. Flows of viscoplastic materials: models and computations. Rheol 64: 135-178.

Noon, A. \& Kim, M. 2016. Erosion wear on centrifugal pump casing due to slurry flow. Wear 364: 103-111.

Hager, A., Kloss, C., \& Goniva, C. 2018. Combining open source and easy access in the field of DEM and coupled CFD-DEM: LIGGGHTS, CFDEM coupling and CFDEM workbench. Computer Aided Chemical Engineering 43: 1699-1704.

Haider, A. \& Levenspiel, O. 1989. Drag coefficient and terminal velocity of spherical and nonspherical particles. Powder Technology 58: 63-70.

Cundall, P. A. \& Strack, O. D. L. 1979. A Discrete Numerical model for granular assemblies. Geotechnique 29: 47-65.

Bitter, J. G. A. 1963. A Study of erosion phenomena parts 1 and 2. Wear 6: 5-21 \& 169-190.

Haugen, K., Kvernvold, O., Ronold, A. \& Sandberg, R. 1995. Sand erosion of wear resistant materials: Erosion in choke valves. Wear 186-187: 179-188. 